\title{
Effect of a pay for performance schemes on improvement of the childhood immunization coverage rates: A literature review
}

\author{
Giorgia Rotundo ${ }^{1}$, Marianna Mauro $^{2}$ and Monica Giancotti ${ }^{*}$ \\ ${ }^{1}$ Department of Legal, Historical, Economic and Social Sciences, Magna Graecia University. Catanzaro, Italy \\ ${ }^{2}$ Department of Clinical and Experimental Medicine, Magna Graecia University, Viale Europa, Catanzaro, Italy
}

\begin{abstract}
Immunization represents the most effective and economical tool available in the field of public health. The use of vaccines led to profound changes in the epidemiology of many infectious diseases, reducing their morbidity and mortality. General practitioners play a key role in the delivery of these type of preventive services. The purpose of this paper is to give a comprehensive overview of the literature evidence on the impact of different Pay for Performance programs in general practice on childhood immunization rates. Most of selected studies showed that childhood immunization rates within a health plan that implemented a robust Pay for Performance program were significantly higher. Ongoing monitoring of incentive programs has important value and is critical to determine the effectiveness of financial incentives plans.
\end{abstract}

\section{Introduction}

Immunization represents the most effective and economical tool available in the field of public health. The use of vaccines led to profound changes in the epidemiology of many infectious diseases, reducing their morbidity and mortality [1]. Maintaining high immunization coverage levels is important to reduce the burden of vaccine preventable diseases and prevent a resurgence of these diseases, particularly in under vaccinated populations [2]. General practitioners (GPs) play a key role in the delivery of these type of preventive services. Indeed, physician recommendations is an important determinant of a patient's decision [3]. In order to motivate physicians to reach higher levels of immunization, in many countries the immunization coverage rates are included as one indicator for achievement in incentives programs [36]. The UK remains in the vanguard of such schemes, with the Quality and Outcomes Framework (QOF) paying out around $£ 1000 \mathrm{~m}(€ 1300$ $\mathrm{m} ;$ \$2000 m) in 2005-2006 to general practices [4,7].

The United States has over 100 private and federal Medicare reward and incentive programs, and Italy and New Zealand are beginning to reward performance in primary care [8]. Under the Pay for performance $(\mathrm{P} 4 \mathrm{P})$ schemes, providers are paid more if they achieve quality benchmarks or demonstrate improvements in the quality of care, they provide [9].

Although most schemes focus on quality, performance objectives could cover a wide range of variables including volume, equity, patient satisfaction, patient safety, and cost effectiveness [10]. The international literature finds that $\mathrm{P} 4 \mathrm{P}$ initiatives are associated with better quality. But it is difficult to determine if the initiatives caused the observed quality improvements, in part because financial incentives usually are employed as one component of an overall quality improvement strategy. Therefore, any quality gains that are observed could be due to payments, or they could be due to other features of the quality improvement strategy, or both [11].
In this context, childhood immunization rates are a particularly instructive measure to consider because all states explicitly cite targeting of this indicator in their written P4P plans [12]. Assessing the effect of $\mathrm{P} 4 \mathrm{P}$ on childhood immunization status might start by testing whether the introduction of a program improved vaccination rates for children living in states that introduced this remuneration scheme [12]. The purpose of this paper is to give a comprehensive overview of the literature evidence on the impact of different $\mathrm{P} 4 \mathrm{P}$ programs on childhood immunization rates. The following section provides the description of the method, section 3 describes the results of this literature review, in section 4 , conclusions and discussions are provided.

\section{Materials and methods}

\section{Search strategy}

This literature review was conducted according to the Preferred Reporting Items for Systematic Reviews and Meta-analyses (PRISMA) statement [13]. (The complete PRISMA Checklist is provided in Supplemental material- Table 1).

Our investigation begins with the definition of the problem about which we want to investigate.

*Correspondence to: Monica Giancotti, Department of Clinical and Experimental Medicine, Magna Graecia University, Viale Europa, Catanzaro, Italy, E-mail: mgiancotti@unicz.it

Key words: childhood immunization rate, financial incentives, general practice, pay for performance, preventive care, primary care

Received: September 11, 2018; Accepted: September 23, 2018; Published: September 28, 2018 
We delineated the problem through the following search questions: $\mathrm{RQ})$ What is the evidence in literature for the effects of financial incentives on childhood immunization coverage rates?

We performed a search of literature using Web of Science, Cochrane Library, PubMed and Google Scholar. Papers were extracted from the database using 4 separate keyword pairs (pay for performance, financial incentives, preventive care, childhood immunization rate ${ }^{*}$ ) to find the most articles focused on this topic. In addition, we used 2 keywords focusing on the primary care setting (primary care, general pract $^{*}$ ), using the Boolean operator AND to identify all relevant papers in the field and to classify articles according to the covered issue.

The search on the database by selected keywords has been extended to title, keywords and abstracts (topics range). The search of literature was performed without no limits of date on the database search. We included articles published and written in English. Some inclusion and exclusion criteria were considered. First of all, we were interested in identifying studies of explicit financial incentives directed at general practitioners which had performance-based contracting. All studies involving the incentives aimed at improving childhood immunization rates in primary care practices were considered.

Meeting abstracts, proceedings papers, letters to the editors and editorials without data were also excluded. All article titles and abstracts identified from the electronic searches were review by the three authors according to the inclusion/exclusion criteria.

\section{Classification of articles by effect on childhood immunization rates}

Following the framework used by Petersen et al. [14] we classified articles according to the effect of the financial incentives on childhood immunization coverage rates, as follow
- positive effects: studies in this area demonstrated a statistically significant improvement

- irrelevant effects: studies showed no significant step change in the variation of coverage rates

- negative effects: studies demonstrated a statistically significant decrease.

\section{Results}

\section{Studies selected}

Our search for eligible studies is summarized in the figure 1. The initial search of electronic databases and reference lists from relevant studies yielded a total of 19.360 titles. Of these, only 11 studies met the inclusion criteria previously described. Because of the heterogeneity between studies, meta-analysis was not possible, and results are presented narratively.

\section{Effect of financial incentives on childhood immunization delivery rates}

Fairbrother et al. [3] examined the effect of different financial incentives on immunization coverage, specifically the percentage of children up-to-date on a variety of immunizations. Physicians were assigned to one of three groups: bonus and feedback, enhanced fee-for-service and feedback, and feedback only and immunization were measured at three points in time, approximately four months apart. They found that there was a $25 \%$ improvement in up-to-date immunization in the bonus group, with no significant changes in the other groups.

Subsequently, the same authors conducted a follow-up to a previous study to analyze whether bonus payments and enhanced fee-
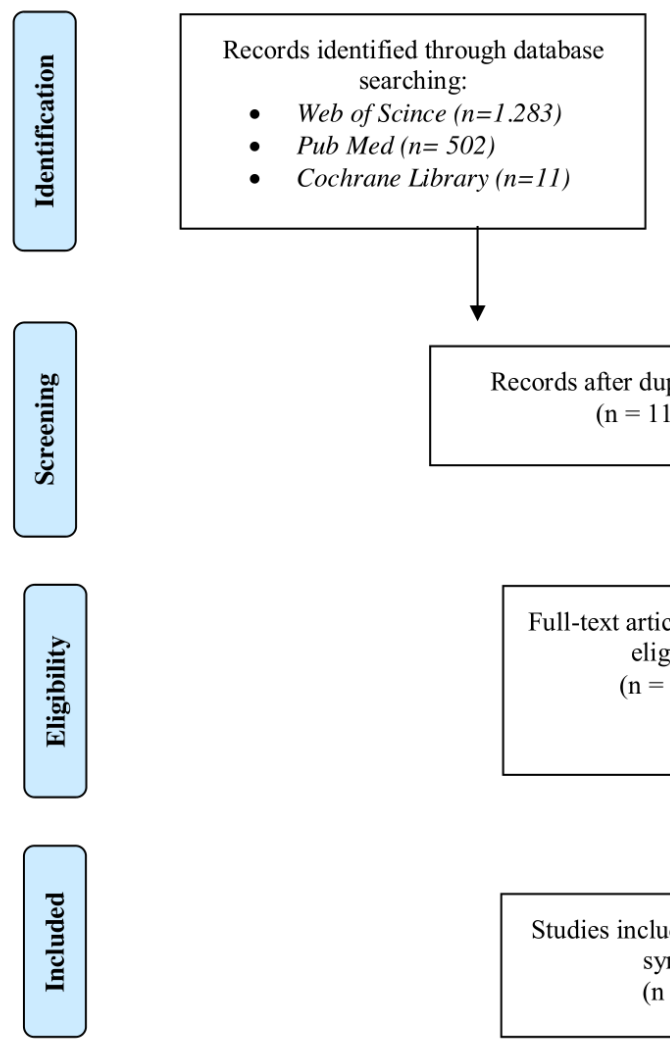

Additional records identified through other sources:

- Google Scholar $(n=17.564)$
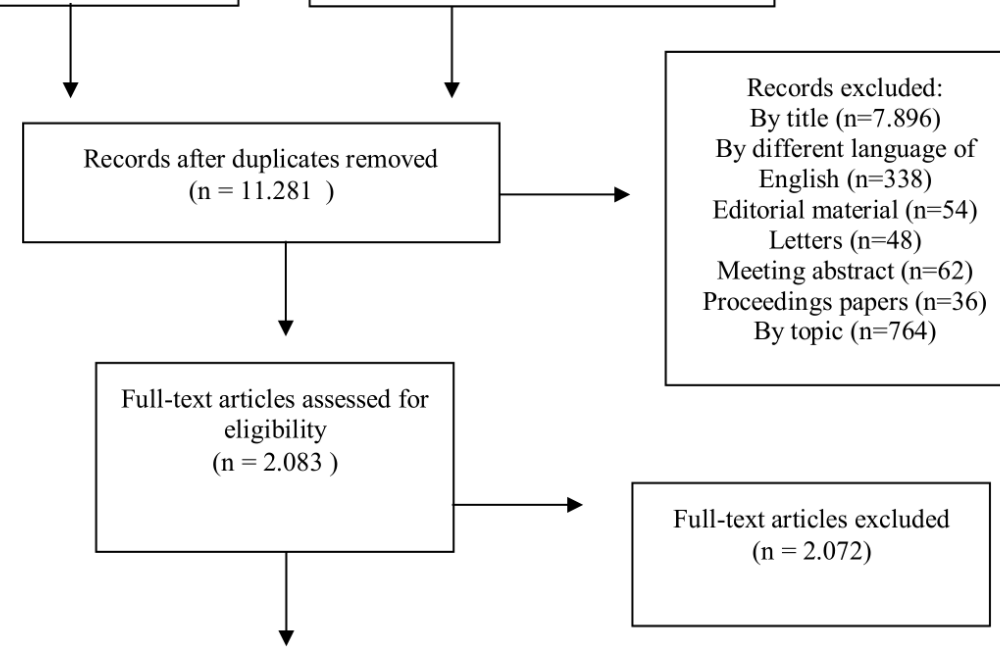

Studies included in qualitative synthesis $(\mathrm{n}=11)$

Figure 1. Prisma flow diagram 
for-service improved immunization rates for children, specifically the percentage of children with up-to-date coverage on immunization. Bonus payments were $\$ 1000$ and $\$ 2500$ for 30 point and 45 -point improvements, $\$ 5000$ for reaching 80 per cent up- to-date coverage and $\$ 7500$ for reaching 90 per cent up-to-date coverage. In the enhanced fee- for-service group, physicians received $\$ 5$ for each vaccine administered within 30 days of its due date and $\$ 15$ for each visit at which all due vaccines were administered. They found that both types of financial incentives increased documented immunization [15].

A study by Felt-Lisk et al. [16] evaluated the effectiveness of the P4P strategy in raising attendance levels at the well- child visits in which the immunization series is delivered. This study found that the two Medicaid $\mathrm{P} 4 \mathrm{P}$ programs raised rates more than the Medicaid national mean.

Chien et al. [17] used two quasi-experimental study designs and corresponding data sources to evaluate the effectiveness of $\mathrm{P} 4 \mathrm{P}$ program over 4-years study period from 2003 to 2007 . The authors found that immunization rates for 2-year-olds rose over the study period from $60 \%$ in 2003 to $80 \%$ in 2007 for all New York Medicaid health plans. The increase for patients including in the incentives program was $7 \%$ greater than that of the comparison health plans when comparing 2003-2005, and 11\% greater when comparing 2003-2007.

In 2006, Estonia started the pay-for-performance quality system (QS) for family doctors (FD). The prevention domain of the Estonian QS for FDs includes clinical quality indicators for children (0-7 years) as follow-up of the child and immunization coverage. The aim of the study by Merilind et al. [2] was to compare differences in immunization rates of Estonian FDs in two different groups: those joined to the QS and those not joined. The target level of immunizations in Estonia is set at 90 per cent and higher. Comparing the two groups of FDs, joined to the QS and not joined, there are significant differences in vaccination coverage in almost all of the vaccinations. Doctors joined to the quality system met the 90 per cent vaccination criterion more frequently compared to doctors not joined to the quality system. Doctors not joined to the quality system were below the 90 per cent vaccination criterion in all vaccinations listed in the Estonian State Immunization Schedule. They conclude that $\mathrm{P} 4 \mathrm{P}$ as a financial incentive encourages higher levels of childhood immunization.

$\mathrm{Hu}$ et al. [12] studied the impact of Medicaid P4P programs on children's immunization status. Using information on the immunization status of a nationally representative sample of children aged 19-35 months, the effect of Medicaid P4P programs on childhood vaccination rates was estimated using difference-in-difference (DD) and difference-in-difference-in-difference (DDD) models. Data were extracted from the National Immunization Survey (NIS), a survey monitoring immunization coverage among children aged 19-35 months living in the U.S. from 1999 to 2011. The study found no overall effect of Medicaid P4P on the chance that children aged 19-35 months had completed the vaccination series. However, there was a 4-percentage point increase in the chance that a child 19-23 months had completed the series. For children aged 19-23 months, the authors found significant increases in the chance that the child had received most components of the series in addition to the series itself. This study provides some evidence that Medicaid $\mathrm{P} 4 \mathrm{P}$ programs may be helpful in improving childhood vaccination rates.

On the other hand, some Canadian studies revealed that the P4P did not produce significant changes on the indicator considered [18-20].
Particularly, Katz et al. [19] evaluated the impact of a P4P program called the Physician Integrated Network (PIN) on childhood vaccination rates in Manitoba. They included all children born between 2003 and 2010 who were patients at PIN clinics receiving P4P funding. They examined the rate of completion of the childhood primary vaccination series by age 2 . Findings suggest that the PIN had a limited impact on vaccination rates.

An analysis in the United States measured the effect of $\mathrm{P} 4 \mathrm{P}$ programs on health care quality, including childhood vaccination [21]; however, the study failed to find evidence that P4P initiatives brought about major improvements in quality of care.

Finally, a search conducted by Fu et al. [22] aimed to compare the combined effect a financial incentive program and a virtual quality improvement technical support (QITS) learning collaborative regard to impact on pediatric immunization coverage. A cluster-randomized trial was conducted among unaffiliated pediatric practices across the United States from June 2013 to June 2014. They found that participation in either a financial incentives program or a virtual learning collaborative led to self-reported improvements in immunization practices but minimal change in objectively measured immunization coverage.

\section{Discussion and conclusions}

In the last years, $\mathrm{P} 4 \mathrm{P}$ programs have become a popular method of encouraging the delivery of primary health care services, although it is still uncertain the real effects on the improvement of delivery rates $[23,24]$.

With regard to childhood immunization, our review has produced mixed results. Most studies showed that childhood immunization rates within a health plan that implemented a robust $\mathrm{P} 4 \mathrm{P}$ program rose at a significantly higher rate than among health plans that did not, despite robust secular trends $[2,3,12,15-17]$.

Contrary, other five relevant studies demonstrated that a $\mathrm{P} 4 \mathrm{P}$ program had no effect on childhood immunization delivery rates [18-22].

However, it must be to take in consideration that no study has shown a negative impact of financial incentives on vaccination rates. The immunization coverage rate is very important for public health and all activities to improve this are necessary. Better outcomes will come with stronger cooperation of primary care team members, government policy and public attitude. This indicator encourages general practitioners to reach high levels of childhood immunization. Most of the previous studies showed physicians joined to the $\mathrm{P} 4 \mathrm{P}$ had better immunization coverage rates than physicians not joined to the program [2].

Our search may be affected by some limitations. First of all, only papers published in English language were reviewed; data published in other languages were automatically excluded from this study. Our inability systematically to review literature in other languages may be considered a weakness. Although we had intended to review the nonEnglish literature, professional language translation services proved prohibitively expensive. Secondly, analysis was necessarily limited to available papers and thus potentially subject to publication bias.

Ongoing monitoring of incentive programs has important value and is critical to determine the effectiveness of financial incentives plans. Our search provides contributions for both research and practice.

In particular, this search can help guide policy makers to determine whether the introduction of specific financial incentives can improve the vaccinations delivery rates for child reducing the risk of illness and mortality. 
On the other hand, P4P programs will continue to develop. According to this, further research is needed to guide implementation of financial incentives in this area and to assess their effectiveness.

\section{References}

1. Carlino C, Aniuskevich A, Morciano L, Franco E, Zaratti L (2012) L'accettabilità delle vaccinazioni negli adulti. Igiene e Sanita Pubblica 68: 885-894.

2. Merilind E, Vðstra K, Salupere R, Kolde A, Kalda R (2014) The impact of pay-forperformance on the workload of family practices in Estonia. Qual Prim Care 22: 109-114. [Crossref]

3. Fairbrother G, Hanson KL, Friedman S, Butts GC (1999) The impact of physician bonuses, enhanced fees, and feedback on childhood immunization coverage rates. $\mathrm{Am}$ J Public Health 89: 171-5.

4. Doran T, Fullwood C, Gravelle H, Reeves D, Kontopantelis E, et al. (2006) Pay-forperformance programs in family practices in the United Kingdom. $N$ Engl J Med 355 : 375-384. [Crossref]

5. Ward K, Hull BP, Leask J (2013) Financial incentives for childhood immunisation-a unique but changing Australian initiative. Med J Aust 198: 590-592. [Crossref]

6. Kirschner K, Braspenning J, Akkermans RP, Jacobs JE, Grol R (2013) Assessment of a pay-for-performance program in primary care designed by target users. Fam Pract 30: 161-171. [Crossref]

7. Campbell S, Reeves D, Kontopantelis E, Middleton E, Sibbald B, et al. (2007) Quality of primary care in England with the introduction of pay for performance. $N$ Engl J Med 357: 181-190. [Crossref]

8. Mannion R, Davies HT (2008) Payment for performance in health care. BMJ 336: 306308. [Crossref]

9. Christianson JB, Sutherland K, Leatherman S (2007) Paying for quality: Understanding and assessing physician pay-for-performance initiatives. Synth Proj Res Synth Rep 13: 24373 [Crossref]

10. Hahn J (2006) Pay-for-performance in health care. In The Library of Congress: Washington, DC Nov 2.

11. Christianson JB, Leatherman S, Sutherland K (2008) Lessons from evaluations of purchaser pay-for-performance programs: a review of the evidence. Med Care Res Rev 65: 5S-35S. [Crossref]
12. Hu T, Decker SL, Chou SY (2016) Medicaid Pay for Performance Programs and Childhood Immunization Status. Am J Prev Med 50: S51-51S57. [Crossref]

13. Moher D, Liberati A, Tetzlaff J, Altman DG (2009) Preferred reporting items for systematic reviews and meta-analyses: the PRISMA statement. Ann Intern Med 151: 264-269. [Crossref]

14. Petersen LA, Woodard LD, Urech T, Daw C, Sookanan S (2006) Does pay-forperformance improve the quality of health care? Ann Intern Med 145: 265-272. [Crossref]

15. Fairbrother G, Siegel MJ, Friedman S, Kory PD, Butts GC (2001) Impact of financial incentives on documented immunization rates in the inner city: results of a randomized controlled trial. Ambul Pediatr 1: 206-212. [Crossref]

16. Felt-Lisk S, Gimm G, Peterson S (2007) Making pay-for-performance work in Medicaid. Health Aff (Millwood) 26: 516-527. [Crossref]

17. Chien AT, Li Z, Rosenthal MB (2010) Improving Timely Childhood Immunizations through Pay for Performance in Medicaid-Managed Care. Health Serv Res 45: 1934 47. [Crossref]

18. Li J, Hurley J, DeCicca P, Buckley G (2014) Physician response to pay-for-performance: Evidence from a natural experiment. Health Econ 23: 962-78. [Crossref]

19. Katz A, Enns JE, Chateau D, Lix L, Jutte D, et al. (2015) Does a pay-for-performance program for primary care physicians alleviate health inequity in childhood vaccination rates? Int J Equity Health 4: 114. [Crossref]

20. Kaczorowski J, Goldberg O, Mai V (2011) Pay-for-performance incentives for preventive care: views of family physicians before and after participation in a reminder and recall project (P-PROMPT). Can Fam Physician 57: 690-696. [Crossref]

21. Mullen KJ, Frank RG, Rosenthal MB (2010) Can you get what you pay for? Pay-forperformance and the quality of healthcare providers. Rand J Econ 41: 64-91. [Crossref]

22. Fu LY, Zook K, Gingold JA, Gillespie CW, Briccetti C, et al. (2016) Strategies for improving vaccine delivery: a cluster-randomized trial. Pediatrics. 10: e20154603. [Crossref]

23. Scott A, Sivey P, Ait OD, Willenberg L, Naccarella L, et al. (2011) The effect of financial incentives on the quality of health care provided by primary care physicians. Cochrane Database Syst Rev 9: CD008451. [Crossref]

24. Huang J, Yin S, Lin Y, Jiang Q, He Y, et al. (2013) Impact of pay-for-performance on management of diabetes: a systematic review. J Evid Based Med 6: 173-184. [Crossref]

Copyright: $\odot 2018$ Rotundo G. This is an open-access article distributed under the terms of the Creative Commons Attribution License, which permits unrestricted use, distribution, and reproduction in any medium, provided the original author and source are credited. 